\title{
Microvascular Free Flaps Reconstruction of Composite Resection Defects
}

\author{
Dr. Gopinathan Sivasankaran
}

\begin{abstract}
Introduction: Buccal mucosa is a major sub site for oral squamous cell carcinoma (SCC) in the Indian subcontinent. The gold standard management of Buccal cancer is Composite resection which creates sometimes large defects. Reconstructive options for Composite resection defects are regional flaps to loco regional flaps to micro vascular free flaps. Currently, micro vascular free tissue transfer is considered as ideal choice for oral cavity reconstruction. This prospective study describes the outcome of Microvascular free flaps reconstruction of Composite resection defects. Materials and Methods: The current prospective study was conducted in the Department of Surgical Oncology at tertiary health care centre. Staging work up done with CECT Scan, X ray chest. Procedure was performed are Composite resection as per standard protocol. Outcome of the surgery with complications, cosmetic and functional outcomes were noted. Results: Total number of Buccal cancer included in our study is 140 and all patients underwent reconstruction by Pedicled (80) or Microvascular flaps (60). In our study, Majority 27 patients (45.0\%) underwent radial free forearm flap followed by ALT flap. Cosmetic outcome and Functional outcome are better with all Microvascular flap. Conclusion: Reconstruction of Composite resection defects are challenging due to their complex three dimensional natures. For large complex defects, Micro vascular free flap provides better Cosmetic and Functional outcome.
\end{abstract}

Keywords: Micro vascular flap,composite resection

\section{Introduction}

Buccal mucosa is a major sub site for oral squamous cell carcinoma (SCC) in the Indian subcontinent, and these tumors are known for recurrence even following adequate treatment $[1,2]$.

Indian Oral cancer is among the top three types of cancers in India [3]. In India, 20 per 100000 populations are affected by oral cancer which accounts for about $30 \%$ of all types of cancer [4]. Over 5 people in India die every hour everyday because of oral cancer (5).

The gold standard management of Buccal cancer is Composite resection (Wide local excision + Manibulectomy + Neck dissection) which creates sometimes large defects. Due to their complex three dimensional natures, defects resulting from surgical ablation constitute major functional and esthetic reconstructive challenges $(6,7)$

Composite resection defect reconstruction has improved with the better knowledge and techniques. It is a surgical challenge to perform reconstruction as structure; function and esthetics have to be restored (8)

Reconstructive options for Composite resection defects are regional flaps to loco regional flaps to micro vascular free flaps. Currently, micro vascular free tissue transfer is considered as ideal choice for oral cavity reconstruction. Various Micro vascular free flap of choice for Buccal mucosa reconstruction are radial free forearm flap, antero lateral thigh flap, fibula flap based on defects.

The characteristics of an ideal free flap for head and neck reconstruction include Pliable, Consistent, large and long pedicle, Possibility of variable size and thickness, harvesting the flap can be consistent and can be done by reconstructive surgeon in the same time of tumor excision and Minimal donor site morbidity. Disadvantages of free flap are failure $(12,13)$. However, free flap transfer cannot be used for all patients at every institute since it requires special techniques and equipment's for microsurgery (7, 9 and 10).

Since it was first described by Song et al in 1982, the radial forearm free flap has become a workhorse flap in head and neck reconstruction (11)

Antero lateral thigh flaps commonly used for large oral cavity defects. Blood supply of the flap is musculocutaneous and septocutaneous perforators of the descending branch of the lateral circumflex femoral artery and its venae comitantes.

Segmental or Hemi Mandibular defects are closed by free fibula flap or radial free flap along with wedge of radius bone. The fibula free flap provides a long, strong segment of bone for use in reconstructive surgery. It can be harvested as a purely osseous flap or can include a large fasciocutaneous component if needed. To date, no other flap is capable of providing such a long segment of bone. Blood supply of the flap is Peroneal vessels.

This prospective study describes the outcome of Microvascular free flaps reconstruction of Composite resection defects.

\section{Materials and Methods}

The current prospective study was conducted in the Department of Surgical Oncology at tertiary health care centre from the January 2014 to September 2017. Each patient was informed and consent was taken to participate in the study.

\section{Inclusion criteria}

Patient eligible for the analysis were those underwent composite resection with an immediate reconstruction with use of free radial forearm flap, antero lateral thigh flap and free fibula flap 
International Journal of Science and Research (IJSR)

ISSN (Online): 2319-7064

Index Copernicus Value (2016): 79.57 | Impact Factor (2015): 6.391

\section{Exclusion criteria}

1) Patient underwent primary closure, skin graft after resection

2) Pedicled flap reconstruction

3) Patient underwent Neoadjuvant chemotherapy

4) Metastatic disease

Detailed clinical history and examination of the patients were recorded. Staging work up done with CECT Scan, X ray chest.

Procedure was performed are wide local excision of primary with Manibulectomy (Marginal, Segmental or Hemi) with neck dissection as per standard protocol. Reconstruction was made with free radial forearm flap, antero lateral thigh flap and free fibula flap based on defects

Outcome of the surgery with complications, cosmetic and functional outcomes were noted. A complication of the procedure divides into early and late. Early complications are Hematoma, Seroma, and wound infection, wound dehiscence, drooling of saliva, Oro cutaneous fistula. Late complications are Trismus, shoulder dysfunction and Parasthesia of the neck.

Cosmetic outcome are divided into excellent, satisfied and fair. Functional outcome are divided into Excellent, satisfied and fair.

Recurrences are divided into local, systemic and both

Data was compiled in MS Excel and checked for its completeness and correctness. Then it was analyzed.

\section{Results}

Total number of Buccal cancer included in our study is 140 and all patients underwent reconstruction by Pedicled (80) or Microvascular flaps (60). 32 patients (53.3\%) belong to 40 50years and male predominance (Table 1).

All patients are squamous cell carcinoma with majority are grade $3(50.0 \%) .29$ patients $(48.3 \%)$ are stage 4 (T4a or N2) group and 28 patients $(46.6 \%)$ are tumour size more than $4 \mathrm{~cm}$ (Table2).

In our study, Majority 27 patients $(45.0 \%)$ underwent radial free forearm flap followed by ALT flap. 15 patients (25.0\%) underwent free fibula flap (Table3).

Major site of reconstruction are mucosa with Mandible $(41.7 \%)$ followed by mucosa, mandible and skin $(25.0 \%)$ (Table3).

Early complications like Hematoma, Seroma, wound infection, wound dehiscence, Drooling of saliva, Oro cutaneous fistula are less common in Micro vascular flap. Late complications like Trismus, shoulder dysfunction and Parasthesia of the neck less common Microvascular flap (Table4)

Cosmetic outcome and Functional outcome are better with all Microvascular flap (Table 5,6 )
Table 1: Patients Characteristics

\begin{tabular}{|c|c|c|}
\multicolumn{3}{|c}{ a. Age } \\
\hline & Number & Percentage $(\%)$ \\
\hline$<40 \mathrm{yrs}$ & 10 & $16.7 \%$ \\
\hline $40-50 \mathrm{yrs}$ & 32 & $53.3 \%$ \\
\hline$>50 \mathrm{yrs}$ & 18 & $30.0 \%$ \\
\hline
\end{tabular}

b. Sex

\begin{tabular}{|l|l|l|}
\hline Male & 38 & $63.3 \%$ \\
\hline Female & 22 & $36.7 \%$ \\
\hline
\end{tabular}

Table 2: Tumor Characteristics

\begin{tabular}{|c|c|c|}
\hline \multicolumn{3}{|c|}{ a. Tumour size } \\
\hline & Number & Percentage \\
\hline$<2 \mathrm{~cm}$ & 10 & $16.7 \%$ \\
\hline $2-4 \mathrm{~cm}$ & 22 & $36.7 \%$ \\
\hline$>4 \mathrm{~cm}$ & 28 & $46.6 \%$ \\
\hline \multicolumn{3}{|c|}{ c. Grades } \\
\hline Grade1 & 10 & $16.7 \%$ \\
\hline Grade2 & 20 & $33.3 \%$ \\
\hline Grade3 & 30 & $50.0 \%$ \\
\hline \multicolumn{3}{|c|}{ d.Stage } \\
\hline Stage 1 & 09 & $15.0 \%$ \\
\hline Stage2 & 09 & $15.0 \%$ \\
\hline Stage3 & 13 & $21.7 \%$ \\
\hline Stage 4 & 29 & $48.3 \%$ \\
\hline
\end{tabular}

Table 3: Reconstruction Characteristics a. Type of reconstruction

\begin{tabular}{|l|l|l|}
\hline & Number & Percentage \\
\hline C. Radial free forearm flap & 27 & $45.0 \%$ \\
\hline D.ALT flap & 18 & $30.0 \%$ \\
\hline E. Free fibula flap & 15 & $25.0 \%$ \\
\hline
\end{tabular}

\section{b. Site of reconstruction}

\begin{tabular}{|l|c|c|}
\hline Only mucosa & 11 & $18.3 \%$ \\
\hline Mucosa + bone & 25 & $41.7 \%$ \\
\hline Mucosa + skin & 09 & $15.0 \%$ \\
\hline Mucosa + skin + bone & 15 & $25.0 \%$ \\
\hline
\end{tabular}

Table 4: Post Operative Complications: a. Early

\begin{tabular}{|c|c|c|c|}
\hline & $\begin{array}{c}\text { Free Radial } \\
\text { forearm flap }\end{array}$ & $\begin{array}{c}\text { ALT } \\
\text { flap }\end{array}$ & $\begin{array}{c}\text { Free fibula } \\
\text { flap }\end{array}$ \\
\hline Hematoma(11) & 04 & 05 & 02 \\
\hline Infection(08) & 02 & 05 & 01 \\
\hline Wound dehiscence(04) & 02 & 01 & 01 \\
\hline Seroma(28) & 14 & 07 & 07 \\
\hline Drooling of saliva(15) & 05 & 05 & 05 \\
\hline Partial flap loss(06) & 02 & 03 & 01 \\
\hline Total flap loss(02) & 01 & 01 & 00 \\
\hline Oro cutaneous fistula(03) & 01 & 01 & 01 \\
\hline$\underline{\text {. Late }}$ & & & \\
\hline Trismus(04) & 01 & 02 & 01 \\
\hline Parasthesia of neck(06) & 02 & 02 & 02 \\
\hline Shoulder dysfunction(02) & 01 & 00 & 01 \\
\hline
\end{tabular}

Table 5: Cosmesis

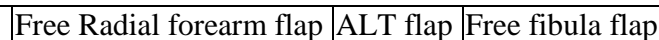

\begin{tabular}{|c|c|c|c|}
\hline & & & \\
\hline Excellent (19) & 13 & 03 & 03 \\
\hline Satisfied(34) & 11 & 12 & 11 \\
\hline Fair (07) & 03 & 03 & 01 \\
\hline
\end{tabular}

\section{Volume 6 Issue 12, December 2017}




\section{International Journal of Science and Research (IJSR) \\ ISSN (Online): 2319-7064}

Index Copernicus Value (2016): 79.57 | Impact Factor (2015): 6.391

Table 6: Functional Outcome

\begin{tabular}{|c|c|c|c|}
\hline & Free Radial forearm flap & ALT flap & Free fibula flap \\
\hline Excellent (17) & 10 & O2 & 05 \\
\hline Satisfied(34) & 14 & 12 & 08 \\
\hline Fair(09) & 03 & 04 & 02 \\
\hline
\end{tabular}

\section{Discussion}

In India, the incidence of oral cavity cancers, is still one of the highest in the world because tobacco products are easily available and the lack of awareness in the community [3].The Composite resection produce complex defects which are difficult to reconstruct. Reconstructive options are Autologous Pedicled or free flap. Each flap has few advantages and disadvantages.

Radial forearm free flap has become a workhorse flap in head and neck reconstruction 14). .Advantages is it provides a skin paddle that is thin, reliable, pliable, and predominantly hairless. Its harvest is safe and consistent (15). Potential donor site complications are Donor site not hidden ,cosmetic ,Tendon exposure ,Fracture of the radius at bone harvest site, Sensory loss in distribution of the superficial radial nerve, Restricted forearm function. Vascular compromise of the hand Potential donor site complications have led some centers to shift toward the Anterolateral thigh flap in recent years (16).

The anterolateral thigh flap is likely the most widely used perforator flap for head and neck reconstruction. Advantages are this flap provides a long, large vascular pedicle, this flap can provide a huge amount of skin, muscle, and fascia with little donor site morbidity, It can be used as a sensate or a flow-through flap $(17,18)$. The anterolateral thigh free flap can technically be combined with iliac bone (31). Disadvantages and potential complications are second-stage thinning, This concept was proposed by Kimura under the operating microscope (micro dissection) (20). This technique is accompanied by an unacceptably high rate of flap failure (21). Patients may experience fatigue and weakness when climbing and descending stairs .Use of split-thickness skin graft (STSG) at the donor site may be complicated by decreased range of motion at the hip and knee joints as a result of adhesion between the skin graft and the underlying muscle (22). Hyperesthesia, anesthesia, numbness, and deceased tolerance to cold may occur in the distribution of the medial branch of the lateral cutaneous nerve of the thigh that is usually sacrificed to protect the perforator $(23,24)$.

Microvascular free fibula flap consists of the fibula bone and associated soft tissue paddle (25). Advantages are as much as $25 \mathrm{~cm}$ of fibula bone can be harvested; Extensive periosteal vascular support allows multiple osteotomies for aesthetic and functional reconstruction of the mandible. This flap can reconstruct angle-to-angle Mandibular defects. Disadvantages are soft tissue component of the flap is limited. The poor arc of rotation of the skin island relative to the bone and its unpredictable vascularity are factors in this limitation. Patients with severe peripheral vascular disease may not be candidates for flap harvest if the lower limb vasculature is involved $(26,27)$.A study by Glastonbury et al indicated that in fibular free flaps, Periosteal ossification of the vascular pedicle is a relatively common occurrence, having been found in 16 of 32 patients (50\%) as soon as 1 month after reconstructive surgery (28).

Early complications like Hematoma, Seroma, Wound infection, wound dehiscence, Drooling of saliva, Oro cutaneous fistula are less common in Micro vascular flap than PMMC flap. Late complications like Trismus, shoulder dysfunction and Parasthesia of the neck more common with PMMC flap than Micro vascular flap

No Valid tools to assess aesthetic and functional outcomes after reconstruction of oral cavity defects. Several studies report aesthetic and functional outcomes, in the form of an assessment by the patient, by the surgeon, or by an independent Professional. Some authors use questionnaires, whereas others use photographs to assess aesthetic outcomes.. We used assessment by patient and two surgeons. Majority of the patient were satisfied. Cosmetic outcome and Functional outcome are better with all Micro vascular flaps.

\section{Conclusion}

Reconstruction of Composite resection defects are challenging due to their complex three dimensional natures. For large complex defects, Micro vascular free flap provides better Cosmetic and Functional outcome.

\section{References}

[1] Walvekar RR, Chaukar DA, Deshpande MS, Pai PS, Chaturvedi P, Kakade A, et al. Squamous cell carcinoma of the gingivobuccal complex: Predictors of locoregional failure in stage III-IV cancers. Oral Oncol 2009;45:135-40.

[2] Pathak KA, Gupta S, Talole S, Khanna V, Chaturvedi P, Deshpande MS, et al. Advanced squamous cell carcinoma of lower gingivobuccal complex: Patterns of spread and failure. Head Neck 2005;27:597-602.

[3] J. K. Elango, P. Gangadharan, S. Sumithra, and M. A. Kuriakose, "Trends of head and neck cancers in urban and rural India," Asian Pacific Journal of Cancer Prevention, vol. 7

[4] R. Sankaranarayanan, K. Ramadas, G. Thomas et al., "Effect of screening on oral cancer mortality in Kerala, India: a cluster randomised controlled trial," The Lancet, vol. 365, no. 9475, pp. 1927-1933, 2005

[5] Bhawna Gupta , Anura Ariyawardana and Newell W. Johnson "Oral cancer in India continues in epidemic proportions: evidence base and policy initiatives"International Dental Journal 2013; 63: 12-25

[6] Pangam N, Thorawade V, Shah R, Jagade M, Nichalani S. Study of Surgical Management and Locoregional Flap Reconstruction in Oral Malighancies. Journal of Dental and Medical Science. 2014;13(5):93-6.

[7] Rudes M, Bilic M, Jurlina M, Prgomet D. Pectoralis Major Myocutaneous Flap in the Reconstructive Surgery of the Head and Neck-Our Experience. Coll. Antropol. 2012;36(2):137-42.

[8] Amin MM, Naseer U, Akhtar A, Awan AA. Pectoralis Major Myocutaneous Flap for Reconstruction of Major Neck Defects. Journal of Surgery Pakistan. 2014;19(2).

\section{Volume 6 Issue 12, December 2017}




\section{International Journal of Science and Research (IJSR) \\ ISSN (Online): 2319-7064 \\ Index Copernicus Value (2016): 79.57 | Impact Factor (2015): 6.391}

[9] Vartanian JG, Carvalho AL, Solange MT, Carvalho, Mizobe L, Magrin J, et al. Pectoralis Major and Other Myofacial/Myoutaneous Flap in Head and Neck Cancer Reconstruction: Experience with 437 Cases at a Single Institute. Head and Neck. 2004;1018-23.

[10] Saitu A, Minakawa H, Saito N, Nagahashi T. Indications and Outcomes for Pedicled Pectoralis Major Myocutaneous Flap at a primary Microvascular head and Neck Reconstructive Center. Modern Plastic Surgery. 2012;2:103-7.

[11] Song R, Song Y, Yu Y, Song Y. The upper arm free flap. Clin Plast Surg. 1982 Jan. 9(1):27-35.

[12] Wei FC, Demirkan F, Chen HC, Chuang DC, Chen SH, Lin $\mathrm{CH}$. The outcome of failed free flaps in head and neck and extremity reconstruction: what is next in the reconstructive ladder?. Plast Reconstr Surg. 2001 Oct. 108(5):1154-60; discussion 1161-2. [Medline].

[13] Dassonville O, Poissonnet G, Chamorey E, Vallicioni J, Demard F, Santini J. Head and neck reconstruction with free flaps: a report on 213 cases. Eur Arch Otorhinolaryngol. 2008 Jan. 265(1):85-95.

[14] Song R, Song Y, Yu Y, Song Y. The upper arm free flap. Clin Plast Surg. 1982 Jan. 9(1):27-35.

[15] Bardsley AF, Soutar DS, Elliot D, Batchelor AG. Reducing morbidity in the radial forearm flap donor site. Plast Reconstr Surg. 1990 Aug. 86(2):287-92; discussion 293-4.

[16] Wei FC, Jain V, Celik N, Chen HC, Chuang DC, Lin $\mathrm{CH}$. Have we found an ideal soft-tissue flap? An experience with 672 anterolateral thigh flaps. Plast Reconstr Surg. 2002 Jun. 109(7):2219-26; discussion 2227-30.

[17] Hanasono MM, Skoracki RJ, Silva AK, Yu P. Adipofascial perforator flaps for "aesthetic" head and neck reconstruction. Head Neck. 2011 Oct. 33(10):1513-9.

[18] Kimata Y, Uchiyama K, Ebihara S, Kishimoto S, Asai M, Saikawa M. Comparison of innervated and noninnervated free flaps in oral reconstruction. Plast Reconstr Surg. 1999 Oct. 104(5):1307-13.

[19] Koshima I, Fukuda H, Yamamoto H, Moriguchi T, Soeda S, Ohta S. Free anterolateral thigh flaps for reconstruction of head and neck defects. Plast Reconstr Surg. 1993 Sep. 92(3):421-8; discussion 429-30.

[20] Kimura N, Satoh K, Hosaka Y. Microdissected thin perforator flaps: 46 cases. Plast Reconstr Surg. 2003 Dec. 112(7):1875-85.

[21] Alkureishi LW, Ross GL. Thinning of the anterolateral thigh flap: unpredictable results. Plast Reconstr Surg. 2006 Aug. 118(2):569-70.

[22] Kimata Y, Uchiyama K, Ebihara S, Sakuraba M, Iida H, Nakatsuka T, et al. Anterolateral thigh flap donor-site complications and morbidity. Plast Reconstr Surg. 2000 Sep. 106(3):584-9.

[23] Huang CH, Chen HC, Huang YL, Mardini S, Feng GM. Comparison of the radial forearm flap and the thinned anterolateral thigh cutaneous flap for reconstruction of tongue defects: an evaluation of donor-site morbidity. Plast Reconstr Surg. 2004 Dec. 114(7):1704-10.

[24] Kuo YR, Jeng SF, Kuo MH, Huang MN, Liu YT, Chiang YC. Free anterolateral thigh flap for extremity reconstruction: clinical experience and functional assessment of donor site. Plast Reconstr Surg. 2001 Jun. 107(7):1766-71.

[25]Huang YC, Leong CP, Pong YP, Liu TY, Kuo YR. Functional assessment of donor-site morbidity after harvest of a fibula chimeric flap with a sheet of soleus muscle for mandibular composite defect reconstruction. Microsurgery. 2012 Jan. 32(1):20-5.

[26] Bodde EW, de Visser E, Duysens JE, Hartman EH Donor-site morbidity after free vascularized autogenous fibular transfer: subjective and quantitative analyses. Plast Reconstr Surg. 2003 Jun. 111(7):2237-42.

[27] Dassonville O, Poissonnet G, Chamorey E, Vallicioni J, Demard F, Santini J. Head and neck reconstruction with free flaps: a report on 213 cases. Eur Arch Otorhinolaryngol. 2008 Jan. 265(1):85-95.

[28] Glastonbury CM, van Zante A, Knott PD. Ossification of the vascular pedicle in microsurgical fibular free flap reconstruction of the head and neck. AJNR Am J Neuroradiol. 2014 Oct. 35 (10):1965-9.

Volume 6 Issue 12, December 2017 www.ijsr.net 